\title{
Implementing Learning Study in Developing Countries: Inhibiting Factors
}

\author{
Sydney Enock Msonde (Corresponding author) \\ Directorate of Library Services, Muhimbili University of Health and Allied Sciences \\ P. O Box +255 65001, United Nations Road, Upanga West, Dar es Salaam- Tanzania \\ E-mail: smsonde@muhas.ac.tz
}

Charles Enock Msonde

The National Examinations Council of Tanzania

P. O Box +255 2624, Bagamoyo Road, Bamaga Area, Dar es Salaam - Tanzania

E-mail: cemsonde@necta.go.tz

Received: December 18, 2016 Accepted: February 05, 2017 Published: March 14, 2017

doi:10.5296/ijld.v7i1.10424 URL: http://dx.doi.org/10.5296/ ijld.v7i1.10424

\begin{abstract}
This study explored the inhibiting factors to the implementation of learning studies in Tanzania secondary schools. Three mathematics teachers formed a learning study to share their experiences on how to implement Learner-Centered Approach (LCA) in their school settings. Teachers were interview at the end of each intervention cycle on the prospects and challenges encountered in the course of implementing learning studies. Classroom observation notes were taken to supplement interview data. All of the qualitative data were analyzed using phenomenographic variation framework. The results show that isolative teachers' working culture, high workload, low remuneration, time consuming nature of learning studies, and school curriculum old recipes were factors that inhibit the implementation of learning studies. We conclude that careful attention should be taken to urgently readdress inhibiting factors for successful and sustainable implementation of learning studies in developing countries.
\end{abstract}

Keywords: Learning study, Variation theory, Inhibiting factors, Developing countries, Teacher learning. 


\section{Introduction}

Studies have shown that the implementation of learning study-guided by the theory of variation improves both teachers and students' learning capabilities. These encouraging results, nevertheless, were evident in studies done in Hong Kong SAR and China Mainland (Lai, 2005; Lo, Pong, and Chik, 2005; Pang, 2002, Pang, 2006, Ma, 1999; Marton and Tsui, 2004; Keung, 2009), Sweden (Runesson, 2005), and Britain (Thabit, 2006). Implementing learning studies in developing countries, mount a new area of study with quit different in culture and context with that of the western and eastern countries. Inspired with positive outcomes of learning study for teacher learning, the need to adapt the model as a platform to engage teachers in reflecting on the best ways to implementing Learner-Centered Approach (LCA) in Tanzania secondary school settings' was imperative. Indeed, this is in line with Author's (2009) suggestions. However, for successful and sustainable practices of learning study, understanding factors that inhibit successful implementation of learning study in developing countries, Tanzania in particular, was vital and, hence; the need for this study.

\section{Theoretical Context}

A learning study has been defined as a systematic effort to attain an educational objective and learn from that attempt. It is an "action research which aims to improve classroom teaching and learning by enhancing teacher professional development" (Keung, 2009; Vikström, 2014). In line with Marton and Lo (2007), it is a designed experiment aiming at making students as well as teachers' learning possible. Thus, lesson and learning studies are teacher directed that allow teachers as practitioners to learn from and their practices (Runesson, 2015), which culminates in improving students learning outcomes (Pang, 2006; Stepanek et al., 2007). Collaboratively, teachers develop a lesson plan, teach and observe the lesson, collect data on student learning, and use their observations to refine their lesson (Marton and Pang, 2006; Pang, 2006; Stepanek et al., 2007). An effective Learning Study improves students learning by promoting high quality teachers' professional development (Pang \& Ling, 2012; Runesson, 2015), among others.

Inspired by the idea of design experiments as well as the Japanese and Chinese teachers efforts to conduct in-depth studies of particular lesson (Keung, 2009; Pang, 2006) culminated into the genesis of learning study. In the same line, Marton and Pang $(2006,2008)$ described Learning Study as a hybrid between designed experiments to the Japanese Lesson Study, and to Chinese collaborative lessons. Figure 1 presents the five steps of the Learning Study described by Lo and Colleagues (2005). These steps include : (1) choosing and defining the object of learning (2) ascertaining student prior knowledge on the object of learning (3) planning and Implementing a designed lesson (4) evaluating the lesson to the extent student have developed the target values (5) reporting and disseminating the results. These steps are cyclic in nature and, enable teachers to reflect the attainability of their pedagogical practices.

Based on these steps teachers select the needy topic from the practiced curriculum, which seem to hamper their daily pedagogical practices (Marton \& Pang, 2008; Keung 2009). Then, the teachers select the object of learning and identify aspects that are critical in understanding the same (Pang \& Ki, 2016). Teachers use their professional experiences about teaching 


\section{Macrothink}

(Pang \& Ling, 2012) to review the problem and findings from the previous studies in dealing with the object of learning. Then, they explore students' prior understanding of the object of learning by administering pre-test and/or interviewing them on issues pertaining to what is to be taught (Pang \& Ki, 2016).

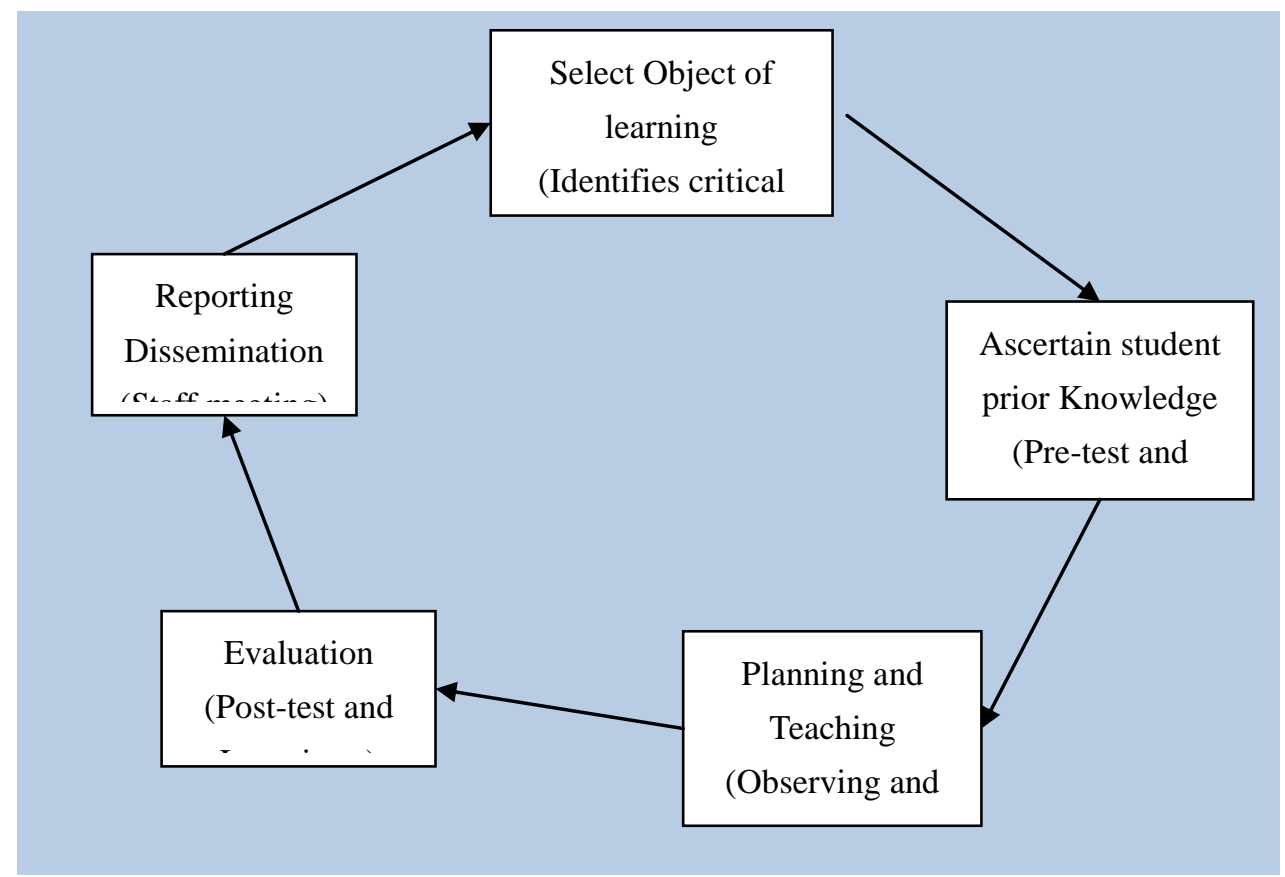

Fig. 1 Learning study cycles

Source: Lo and Colleagues (2005)

Results of this exploration are used as basis for collaborative planning and instruction of a lesson. Teachers normally reflect on the performance of the lesson inspired to student learning, and revise as well as re-teach the lesson if deemed necessary. Finally, the lesson is evaluated in the basis of the post-test and/or post students' interview on the way they experienced what was taught in commensurable terms (Pang, 2006). Normally, the findings are documented; disseminated to the large public and lessons are video recorded.

A learning study is grounded by the Theory of Variation (Marton \& Pang, 2006; Pang \& Marton, 2003). Teachers practice their lessons focused on specific critical aspects of an object of learning aiming at achieving student capabilities (Marton, 2015). Thus, a learning study is effective due to its goal focused and theoretically grounded. It is a Learning Study in three senses because through it students benefit by having good understanding of the object of learning, teachers learn through the process on good ways of handling the object of learning, and the researcher on the other hand, learns the way theory informs practices (Marton \& Pang, 2006; Pang, 2006). Given these benefits of the learning study, the critical question in this study was "what inhibiting factors would be evident if this model was implemented in developing countries such as Tanzania, which differs in terms of culture and context compared with that of western and eastern counties. 


\section{$\triangle$ Macrothink}

\section{Study Design}

This study was done in two major phases. The teachers were engaged in learning study cycles to share their experiences on the best way to practice LCA. Two research LCA lessons were prepared, enacted and evaluated. The first lesson in the first phase was meant for form two secondary school students. On the other hand, the second lesson in phase two was designed for secondary school form three students. Both lessons were in accordance to Tanzania's secondary schools mathematics syllabus. The teachers were involved in pedagogical design and implementation of LCA in classroom settings. They also had reflective meetings to evaluate how individual teacher handled the learning object as well as the challenges they experienced during the learning study cycles. Then, some suggestions and revisions were made for further improvement of the next lesson.

\section{Research Methods}

\subsection{Setting and participants}

This study was conducted at one community secondary school in Morogoro region. The secondary school was purposefully selected based on willingness of mathematics teachers and the school administrator to host and participate in the study. At the time of conducting this study, the 15 teachers in a research school participated in a two day workshop to capacitate teachers on learning study. Three mathematics teachers who later formed a learning study group were among participants in a workshop. The three mathematics teachers who formed a learning study group, were studied on the manner they were experiencing LCA before and during two learning study rounds. For confidentiality in this study, these teachers were assigned pseudonym names of TA, TB, and TC. Their characteristics are shown in Table 1. These teachers were studied on the manner they were experiencing LCA before and during three learning study rounds.

Table 1: Participants (teachers) Attributes

\begin{tabular}{|c|c|c|c|}
\hline Characteristics & Teacher A & Teacher B & Teacher C \\
\hline Academic level & Form six & Form six & Form six \\
\hline $\begin{array}{l}\text { Professional } \\
\text { level }\end{array}$ & Diploma in education & Diploma in education & Diploma in education \\
\hline $\begin{array}{l}\text { Year } \\
\text { experience }\end{array}$ & 6 & 5 & 8 \\
\hline $\begin{array}{l}\text { Major Subject } \\
\text { specialization }\end{array}$ & $\begin{array}{l}\text { Mathematics } \\
\text { physics }\end{array}$ & $\begin{array}{l}\text { Mathematics and } \\
\text { Chemistry }\end{array}$ & $\begin{array}{l}\text { Mathematics } \\
\text { Biology }\end{array}$ \\
\hline
\end{tabular}

Teacher training New curriculum of New curriculum of Old curriculum of 


\begin{tabular}{|l|l|l|l|l|}
$\begin{array}{l}\text { Teacher's } \\
\text { workload }\end{array}$ & $\begin{array}{l}30 \text { periods per } \\
\text { 5days-week }\end{array}$ & $\begin{array}{l}36 \text { periods per 5 days- } \\
\text { week }\end{array}$ & $\begin{array}{l}30 \text { periods per 5 days- } \\
\text { week }\end{array}$ \\
\hline $\begin{array}{l}\text { In-service } \\
\text { learning }\end{array}$ & $\begin{array}{l}\text { Attended once LCA } \\
\text { seminar }\end{array}$ & $\begin{array}{l}\text { Did not attend any } \\
\text { seminar }\end{array}$ & $\begin{array}{l}\text { Attended once LCA } \\
\text { seminar }\end{array}$ \\
\hline $\begin{array}{l}\text { School } \\
\text { responsibility }\end{array}$ & $\begin{array}{l}\text { Assistant Academic } \\
\text { Master }\end{array}$ & School Bursar & $\begin{array}{l}\text { Discipline master and } \\
\text { Head of mathematics } \\
\text { department }\end{array}$ \\
\hline $\begin{array}{l}\text { Group } \\
\text { responsibility }\end{array}$ & Member & Secretary & Chairperson \\
\hline
\end{tabular}

\subsection{Data collection}

Data collection protocol includes interviews, classroom observations, and teacher's reflective journals. The teachers in the learning study group were interview before and immediately after teaching the lesson. The interview focused on the way teachers valued working together in lesson planning, teaching, reflecting from their actions as well as the prospects and constraints for implementing learning study in Tanzanian context. Each interview was audio-recorded and lasted for approximately 45 minutes. The audio recordings were transcribed verbatim and the transcripts were sent to the respective interviewed teachers for review and idea improvement. There were no specific ideas or comments received from any of the interviewed teachers.

The researchers designed classroom observational checklist. The classroom observations intended to determine the manner teachers reacted as well as felt during learning study activities. Each observation was video-recorded and lasted for about 60 minutes. The video-recordings were transcribed verbatim and teachers (respondents) were given their respective transcripts for review and further idea improvement. Moreover, the teachers also filled in the reflective journal at the end of each research lesson. The reflective journals, together classroom observation supplemented the interview data that revealed the way teachers were experiencing LCA practically.

\subsection{Data analysis}

Analysis of interviews, classroom observation, and the teacher's journals followed the phenomenography conventions (Pang, 2006). All of the interview transcripts, classroom observation, and teacher's reflective Journals were coded by the second author, and generated a set of main themes (main codes) and sub-themes (sub-codes). The researcher consistently improved the code description for more than two rounds. A number of recurring codes were clustered into main-codes or themes (Saldaña, 2010).

In order to establish trustworthiness, the sub-code (sub-theme) descriptions, along with their 
associated examples were given to the first author for deeper checking. Code ratings from the second author were compared with those of the first. The researchers were in agreement for 26 out of 33 sub-themes. Statistical analysis showed the level of agreement of .819 (Cohen's kappa), which demonstrate an excellent inter-coder agreement (Gwet, 2012). The researchers resolved the earmarked discrepancies through negotiation. Later, the first author refined the themes and re-coded the data using the refined coding scheme, which comprised 11 main themes.

\section{Results}

Implementing learning study was not a straight forward. The culture of working together was not a common practice for teachers in Tanzania secondary school. The results presented reveal the factors hindering the implementation of learning in a Tanzanian secondary school. Five themes related to factors contributing to the success of implementing learning study were identified. They included school administrative support, teachers' willingness, existing challenges within the curriculum, researcher as exemplar, and perceived positive learning study feedback.

\subsection{Inhibiting factors in implementing learning study}

Teachers' working together was not a straight forward phenomenon in Tanzania schools. After each phase, teachers were interviewed, wrote their journals and were observed in classroom teaching to realize the challenges they faced during the implementation of the learning study activities. Five key themes were categorized as factors inhibiting the implementation of learning studies. They included teacher's isolative dominance culture, huge workload, and time consuming nature of learning studies. Other factors are such as old recipes within a new school curriculum as well as lack of incentives. Each theme (factor) is described in subsequent sections.

\subsection{The isolative dominance teachers working culture}

Data revealed that it was not common for teachers to work collaboratively in the research school under study. They argued that observing one fellow teacher teaching in the classroom would mean to assess someone's teaching performance. Such acts are only done by school inspectors. Teachers thought once one becomes a qualified professional teacher, his or her profession assessment seizes. They forgot that professional learning is about experiencing differences (Marton, 2015; Runesson, 2015), and is an ongoing process that extends from initial teacher professional development to death. The teachers views were exemplified in following excerpt:

I think it is not common to go in the class and observes someone teaching. Ideally one may view it as a double assessment in their profession while s/he has been, trained, qualified and passed through single lesson teaching practice (SLTP) and Block Teaching Practice (BTP) profession assessments. So many teachers do not like, I think it requires more effort to sensitize them (TA).

The above excerpt depicts the teachers' misconceptions and rigidity to adopt new innovation 
due to their previous beliefs and experiences (Hora \& Holden, 2013). As such, teachers continued to work in isolation as well as developed the sense of conservatism, and were interested in individual perfection rather than communal gain. Such a situation can be explained in terms of the fact that teachers realized that the theoretical premise was contradictive to the previously held beliefs (Runesson, 2015) that need to be unfolded. There were no ideas concerning how teachers could share particular knowledge in order to improve their comprehension as well as practical teaching capabilities. These ideas were reflected in the below excerpts:

You know some of teachers believe on them, and do not bother about collaborating and exchanging of views with their fellows. I think culture also affected to some extent. But we have been in a team of 3 teachers now; and experienced the learning studies and its importance. There are no any problems for us because we share experiences and teaching ideas. Probably, other teachers should be educated to do the same (TB)

It is individualism some times. You know with respect to our culture some teachers think that they know everything, and sharing experiences was wasting of time (TC)

These excerpts indicate that teachers had attendant problems of working in isolative manner. They believed that what they were taught in initial teacher professional development and/or seminars was final and complete. What seemed important for them, was how skillfully individual teachers do accomplish, than what teachers together would achieve in a bid to enhance students learning. Indeed, it is the manifestation of the manner these teachers were trained in teaching profession. Teachers were oriented in the teaching profession through transmittal ways of learning prior to their involvement in the learning study cycles. They believed what was taught as true knowledge that could not be modified. As such, they were not used to learn in collaborative manner, which would be conceived as new way of teacher learning (Pang \& Ling, 2012). It seemed that the individualism culture showed by teachers may hinder the perfection of learning study implementation in Tanzania schools, unless they are well sensitized.

\subsubsection{Overloaded teacher's workload}

It was also evident that three teachers engaged in this study had overloaded number of periods per week. It was due to the scarcity of mathematics teachers that made each of them to have more than 30 periods per week, an average of at least six (6) periods per day. Teachers felt that they were so occupied and, indeed, it become difficult for them to have an ample time for their professional collaborations. To have collaborative professional activities, they required extra time to use out of normal school schedule, which was challenging. These ideas were elaborated in excerpts below:

We do not have much time for discussing especially when we have many periods. For example, I have 30 periods and I'm teaching five streams. Once I finish one period, I prepare for another one. It affects me because you do not have time for relaxing or meet with my fellow teachers for some idea exchange especially when you find a difficult topic (TA).

Learning study processes are time consuming, and we teachers are overloaded with lot of 
periods for classroom teaching. For example, I have 42 periods per week which makes hard to have time for sharing pedagogical experiences with fellow teachers (TC)

The ideas generated from the above excerpts reveals that one of the big challenges in implementing learning study in Tanzania schools at the moment lack of collaborative teaching culture as well as teacher workload to implement learning study. This is because the introduced Secondary School Development Programme (SEDP) created a mismatch between teachers and students (Wedgwood, 2007). As such, there is outcry of teachers' inadequacy all over the country. Scarcity of teachers in various subjects including mathematics, made teachers to be overloaded. As a results, an ample time for teachers working together becomes minimal, which become a challenge in the course of implementation of learning study activities.

\subsubsection{Time limitation working in learning studies}

The teachers indicated that implementing learning study cycles activities require a lot of time. They had a view that learning study professional activities requires teachers to have extra time to deal with difficult phenomenon they identified. Since teachers had large workload to accomplish, it become so challenging for them to have extra time to perform collaborative professional activities which are time consuming in nature. In such a situation, teachers were eager to use weekends to accomplish learning study activities, which also was a challenge. These ideas were evident in the excerpts below:

One of the big challenges to be honest is time consuming nature of the learning study itself. Many teachers have large number of periods per week, and so we had some difficult to find an ample time to meet together. We wait till after class hours or weekend days where you can share our ideas or experiences (TB).

The first challenge is this process of learning study is time conscious versus our workload. You find that we are few mathematics teachers with a lot of periods. But learning study cycles requires enough time which is so difficult to obtain (TA).

Although teachers acknowledged the significance of learning studies in their learning, the processes of its cycles seemed to be time consuming in nature. Identifying the object of learning, and its related critical features required much time. Moreover, designing and deliberating the lesson collaboratively, and reflecting from it seemed to consume much of their time. This line of thinking was influenced by the nature of workload teachers had, as well as the nature of individualism ways of learning teachers were oriented to. However, learning study professional activities do not require teachers convene professional meetings every day. The crux of learning study is to enable teachers work together to resolve their professional common challenges, specifically, on how to deal with complex objects of learning that seemed difficult to them as well as to their students. And by so doing, teachers share their experiences, reflected from their practices and learn from each other in particular time set. 


\subsubsection{Teacher's discouragement from lack of incentives}

As was pointed out in previous sections, teachers overload versus time consuming nature of learning study professional activities, required teachers to use extra time out of the normal school schedule. The teachers claimed extra time meant extra money to sustain their life. The low salary they receive lack of incentives made them unable to sustain their daily living. As such, they were forced to look for alternative activities that would provide them with some extra money for their up keeping. Therefore, most of the teachers became occupied in such a way that they had inadequate time for doing collaborative tasks. The excerpts below exemplify these ideas:

Another challenge is lack of motivation and incentives. Many teachers look at extra money for their well- up keep, hence, hesitating to devote their extra time because as you know, our salaries are very low (TB).

So, we need also to find extra time out of the class, but many of teachers use this time for other activities so that they can find other income (money). Because you know we are underpaid and thus I have to look at other alternatives to get some money... you find this may probably not encourage some teachers to concentrate in learning study activities (TC).

The above excerpts imply that teachers were underpaid as well as lacked incentives that could motivate their job perfection. Job satisfaction was important in encouraging teachers to use even their extra time for collaborative professional activities in order to promote not only their learning but also enhance students learning. It was evident that teachers were overloaded with classroom teachings. Such a situation led teachers fail to have enough time for collaborative professional activities during normal school schedule. As such, extra time was used either for collaborative professional activities or for performing extra duties that would generate extra income to sustain their living. Under these circumstances, teachers may negatively be motivated to enable them participate in learning study activities, which could get some huddles in the course of its implementations.

\subsubsection{Old recipes within a new established school curriculum}

The teachers in the learning study group had the opinion that the established curriculum had old recipes, which may hinder their effective implementation of the learning study professional activities. Although the curriculum insist on collaborative students' learning, others mechanisms for implementing the curriculum reflected old ways of doing things. For example, textbooks were packed with content that emphasizes mathematical operations skills whereas the national examinations board examines the same. In that manner, conceptual learning as well as knowledge usability was jeopardized. They had the view that the learning study required them to go beyond what is seeable in the curriculum in order to provide students with deeper thinking in their real life context. These lines of thought are evident in following accepts:

Currently, our curricula, especially the mathematics one, focus on developing students mathematical operations skills. Even the text books that we use and their associated examples are written with a focus on solving mathematical problems. Therefore, if you teach students 
mathematical conceptual learning, off course they will understand, but examination paper will come contrary to what they had learnt. Thus, I see this as one of the big challenge. (TA)

You know, learning study discusses how to make learners learn beyond the classroom. But the curriculum does not emphasize conceptual learning rather mathematical operations skills. For example the lesson I taught in the class was about arc length. But you cannot find textbooks that elaborate or associate arc length with part of bicycle tires, or roundabouts as I did in the class. That is a big problem, and I think it is high time to advice appropriate curriculum change to enable knowledge learnt be explained in terms of students real life encounter. (TC).

From teachers excerpts one realizes there are inadequacies in the curriculum. Limiting the curriculum to mathematical operational skills content hinders teachers to go beyond what is stipulated in the curriculum. However, the learning study focuses on what students are expected to learn (i.e object of learning). In that way, it makes teachers think deeper in developing certain pattern of variation and invariance (Marton, 2015) in order to help students to discern and focus on identified critical aspects (Pang \& Ki, 2016) in relation to their practical life. Mathematics like any other subjects requires one to go beyond operational skills, which is only insisted in the recent textbooks and the national examining board. As teachers become replicators of what is stipulated in the syllabus, challenges are ironically seen as minimal, hence demoralizing teachers from collaborating together to resolve some emanating professional problems.

\section{Discussion}

This study revealed that the teachers' societal cultural orientations, large workload, and old recipes dominance in the new school curriculum were among the factors that inhibit teachers from working collaboratively. Other factors include time consuming nature of learning study activities; low salaries as well as lack of incentives discourage teachers to adopt collaborative working initiatives. With only adoptive technical professional knowledge acquired from traditional TPD encouraged teachers to working in isolation. In line with these findings, McLaughlin and Talbert's (2006) study found that that changing dominated individualistic culture was a great challenge,

In large part effort to mandate community has failed because this kind of change cannot be commanded into existence. Teacher learning communities change culture in a way difficult to accomplish in any profession, but most especially in the isolated, individualistic lives of schoolteachers (p. 11)

Given these realities, it is our conviction that three core determinant factors have significance influence on isolative or collaborative working among teachers. These factors are influenced at three levels: national, school, and individual teacher. At the national level, educational policy has great influences. Although statements of educational intent may be encouraging, its operationalization into curriculum for implementation however, may be vague. While education and training policy of Tanzania directs learning to be students-centered, it seems 
the education curriculum prepares teachers to take those responsibilities theoretically without taking into account the prevailing schools' environment. This is in line Author (2006) findings that teacher educators in Tanzania neither collaborate themselves nor engage with prospective teachers collaboratively in day-to-day instructions to unfold the foreseen challenges. Similarly, the intention to develop respective teachers' as well as students' capabilities become jeopardized by the old recipes stressed within new curricula. To discourage teachers to work in isolative manner, necessitate the need to redefining the teacher education and school curricula so as to incorporate collaborative TPD for both pre-service and in-service teachers in practical terms.

In addition, teachers' workload is another strand impacted by the national recruitment priorities for education expansion. The increase in enrolment of students and expansion of schools through the SEDP 2005-2009 leaves teachers with unimaginable workload of 30-40, instead of 12-24 periods per week. Such a situation minimizes the teachers' opportunity to work together. The failure of the teachers to work collaboratively was associated with low pay and lack of incentives to motive them during teaching. As Schwille, Dembele, and Schubert (2007, p. 41) report,

In many developing countries, the teaching force is demoralized and fractured. Teachers, especially in rural areas are frequently paid little and late; their education and training needs are neglected and they are mired in bureaucracies that support neither their effective performance nor their career progression on their jobs...teachers very often feel powerless, either to create positive learning experiences and outcomes for their pupils or to improve their own situation.

To perpetuate the collaborative learning environment among teachers in schools, teachers' recruitments should be both qualitatively and quantitatively improved in order to minimize teacher's time constraints. School's administration and community support are paramount vital in enhancing teachers collaborative working. When teachers are recognized, valued, respected, and encouraged to work jointly in facing common challenges prevailed in the schools, they are more likely to develop sophisticated understanding (Vikström, 2014), and sense of togetherness toward high purpose of improving students' learning. Capabilities to untangle some complex issues in schools such as complex discipline topics such as the LCA pedagogy, cannot be handled with an individual teacher, rather with school teachers, collaboratively. As Samaras, Freese, Kosnik, and Beck (2008) argue Teachers in learning communities become 'Inter-dependent innovators, problematizing and reflecting from their practices, sharing dependent concerns and new ideas, as well as success and failure.... which creates a sense of ownership of their innovative endeavors' (p. 3).

Indeed, this is possible when teachers are encouraged to resolve challenges together, provided with appropriate resources and/or incentives required, valued, respected as well as recognized from their contributions by their school's administration and community. In the same vein, McLaughlin \& Talbert (2006) claim school administration support is a key success for school-based teachers' learning community. This is specifically, in sustainable practices of lesson study and learning study (Stepanek et al., 2007). With the help of school teacher 
professional mentors, teachers managed to work jointly in handling challenging issues including but not limited to complex objects of learning. Although school mentors or guiders are likely to encourage teachers to work together, nevertheless, they are inadequate in number to sustain this need. As Schwille, Dembele, and Schubert (2007) argue, 'The basic assumptions of school-based training-namely that there are sufficient schools to offer appropriate training environments and enough of qualified teachers to act as professional mentors to trainees- are often difficult to meet in low income countries'. This statement is especially true in the Tanzanian context where there is inadequate in number of mentors or guiders.

Moreover, individual teacher's attributes are crucial in determining whether teachers work in isolation or collaboratively. The nature of TPD individual teachers received perpetuates teacher's isolative or collaborative working culture. Data revealed that when teachers experienced their professional training in a traditional TPD previously, they tend to adopt what is taught as true and scientific knowledge to follow which do not need to change (adoptive technical knowledge). The variability among teacher educators' orientations increase disparities among school teachers that even complicates possibilities for their collaboration. Each teacher believed what he/she was taught as perfect than the knowledge acquired by his/her colleague. In that way, when faces challenges in their daily practices, they confront them in isolation, which mostly resulted in regurgitating their traditional professional practices they earlier perceived as correct. Nelson (2009) argues teacher learnt in non-collaborative TPD mostly renegotiate new knowledge in isolation, and indeed, tends to implement curriculum goals as set. As such, teachers become technicians with prescribed technical knowledge, which is considered to be codified or prove knowledge that resides in academic specialists.

Nevertheless, those trained in collaborative TPD develop eagerness to act, willingness for change, open-mindedness, and readiness to face professional challenges. These are critical aspects that enable individual teachers to see educational innovations as social human constructed that are prone to changes within contextual-temporal variations. These eagerness attributes prompts teachers to work jointly in facing professional challenges encountered within school context and cultural orientations. As teachers become valued and respected with the school administration to their myriad innovative contributions, with time, they may change their previous isolative self-images. Thus, in doing so, they may develop new knowledge and skills through their various renovations obtained jointly, which is practical and reflective comprehension. It is through sharing of experiences as well as learning from their practices, the individual teacher practical knowledge is enhanced (Elliot, 2007). Hence, collaborative TPD models such as action research (Elliott, 2007), lesson study (Stepanek et al, 2007), learning study (Keung, 2009; Pang, 2006), to mention a few; become essential means for enhancing teacher practical learning experiences (Runesson, 2015).

\section{Conclusion}

Based on the findings explained in this study, three interlinked conclusions can be made. First, the nature of TPD teachers acquired during initial and/or in-service professional learning 
inculcates the sense of teachers working in either isolation. Similarly, centralized education system and education policy influences the manner teachers are trained, and the kind of knowledge they acquire, which is reflected with the nature of TPD they received. Second, the culture of working together was not a common practice for teachers in Tanzania secondary school. As such, implementing learning study was not a straight forward. In that regards, when teachers are faced with the LCA pedagogical challenges they simply assimilated previously learned traditional experiences during initial and/or in-service trainings. Third, successful implementation of learning studies in developing countries like Tanzania need a deliberate effort to address the inhibiting factors (eg. high workloads, isolative working culture, and old recipes within a new school curriculum among others) earmarked in this study in order to promote teacher professional development in a learning study setting.

\section{Acknowledgement}

We humbly appreciate to all anonymous participants and reviewers of this study

\section{References}

Akerlind, G. s. (2005). Academic growth and development-how do university academics experience it? Higher education, 50, 1-32.

Elliott, J (2007) Reflecting where the action Is: The selected works of John Elliott, Routledge.

Gwet, K. L. (2012). Handbook of inter-rater reliability: The definitive guide to measuring the extent of agreement among multiple raters: Advanced Analytics Press.

Hora, M. T., \& Holden, J. (2013). Exploring the role of instructional technology in course planning and classroom teaching: Implications for pedagogical reform. Journal of Computing in Higher Education, 25(2), 68-92.

Keung, C.C. (2009). Cultivating communities of practice via learning study for enhancing teacher learning, KADI journal of educational policy, 6 (1), 81-104.

Lai, T.C. (2005). The use of learning study to enhance teachers' professional development: A case study. Unpublished M.Ed Dissertation. Hong Kong: Hong University.

Lo, M. L., Pong, W.Y., and Chik, P.M. (2005). For each and every one: Catering for individual differences through learning studies. Hong Kong: Hong Kong University Press.

McLaughlin, M. W., \& Talbert, J. E. (2006). Building school-based teacher learning communities: professional strategies to improve student learning. New York: Teachers College Press.

Marton, F. (2015). Necessary conditions of learning. London, UK: Routledge

Marton, F. and Pang, M.F. (2006). On some necessary conditions of learning. The Journal of the Learning Sciences, 15(2), 193-220.

Marton, F. and Pang, M.F. (2008). The Idea of Phenomenography and the pedagogy of 


\section{Macrothink}

International Journal of Learning and Development ISSN 2164-4063 2017, Vol. 7, No. 1

Conceptual Change, In S. Vosniadou (Ed.) (2008). International Handbook of Research on Conceptual Change (pp 533-559), New York: Routledge.

Marton, F. and Lo, M L. (2007) Learning from the "Learning Study". The Journal of Teacher Education and Research, 14 (1), 31-44.

Marton, F., and Tsui, A.B.M. (2004). Classroom discourse and the space of learning. Mahwah, NJ: Lawrence Erlbaum Associates, Publishers.

Ma, L.P. (1999). Knowing and teaching elementary mathematics: Teachers' understanding of fundamental mathematics in China and the United States, Mahwah, NJ: Lawrence Erlbaum Associates.

Author. (2006). Innovation in learner-Centered approach: Formative evaluation of the implementation of new teacher education curriculum in Tanzania. The M.A Education Dissertation (Unpublished). Dar es Salaam: University of Dar es Salaam.

Author. (2009). Shifting teachers from teaching to learning in Tanzania schools: Is it possible? Journal of Education and Development, 1(1), 14-24.

Nelson, T. H. (2009). Teachers' collaborative inquiry and professional growth: Should we be optimistic? Science Education, 93(3), 548-580.

Pang, M.F. (2002). Making learning possible: The use of variations in the learning school economics. Unpublished PhD Thesis, Hong Kong: University of Hong Kong.

Pang, M. F. (2006). The Use of Learning Study to enhance teacher professional learning in Hong Kong. Teaching Education, 17(1), 27-42.

Pang, M. F. and Ki, W. W. (2016). Revisiting the idea of "critical aspects". Scandinavian Journal of Educational Research, pp. 1-14

Pang, M. F. and Ling, L. M. (2012). Learning study: Helping teachers to use theory, develop professionally, and produce new knowledge to be shared. Instructional Science, 40(3), 589-606

Pang, F.M., \& Marton, F. (2003). Beyond Lesson Study: Comparing two ways of facilitating the grasp of two economic concepts. Instructional Science , 31(3), 175-194.

Runesson, U. (2005). Beyond discourse and interaction. Variation: a critical aspect for teaching and learning mathematics. The Cambridge Journal of Education, 35(1), 69-87.

Runesson, U. (2015). Pedagogical and learning theories and the improvement and development of lesson and learning studies. International Journal for Lesson and Learning Studies, 4(3): 186-193

Saldaña, J. (2010). The coding manual for qualitative researchers. London: SAGE Publications Ltd

Samaras, A.P., Freese, A.R., Kosnik, C., \& Beck, C. (Eds.). (2008). Learning communities in practice . New York: Springer. 


\section{Ml Macrothink \\ International Journal of Learning and Development \\ ISSN 2164-4063 2017, Vol. 7, No. 1}

Schwille, J., Dembele, M. and Schubert, J. (2007). Global perspectives on teacher learning: Improving policy and practice. Paris: UNESCO-International Institute for Educational Planning.

Stepanek, J., Appel, G., Leong,M., Mangan, M.T., Mitchell, M. (2007). Leading Lesson Study: A Practical Guide for Teachers and facilitators. London: Corwin Press.

Thabit, A.M. (2006). Teachers' awareness of dimensions of variation: A mathematics intervention project. In Hewitt, D. (2006) Proceedings of the British Society for Research into Learning Mathematics 26(1), Department of Educational Studies, University of Oxford.

Vikström, A. (2014). What makes the difference? Teachers explore what must be taught and what must be learned in order to understand the particulate character of matter. Journal of Science Teacher Education, 25(6), 709-727.

Wedgwood, R. (2007). Education and poverty reduction in Tanzania. International Journal of Educational Development, 27(4), 383-396.

\section{Copyright Disclaimer}

Copyright for this article is retained by the author(s), with first publication rights granted to the journal.

This is an open-access article distributed under the terms and conditions of the Creative Commons Attribution license (http://creativecommons.org/licenses/by/3.0/). 